\title{
Repeated Weld Repair and its Influence on Welded Carbon Steel
}

\author{
NurAzida CheLah, Muhamad Hellmy Hussin
}

\begin{abstract}
Weld repair usually comprises of mechanical removal of weld part and redisposition of the filler wire using the same parameters. The defect may be removed by carbon arc gauging and grinding or machining. The strength and the microstructure of the material will changed when the repeated weld repair is applied to the material at the same area. The purpose of this study is to compare and identify the angle of distortion, hardness, and tensile strength and bend strength and to analyze the macro and microstructure between repairing method using carbon arc gauging and mechanical grinding process with the same number of repairing sequence. The result proved that repairing A36 steel increased the strength of the material itself but the ductility was decrease when the number of repair increases. It can be concluded that, the repair using carbon arc gauging can't be applied to repair weld joint for material because it's more significant to change the material process compared to mechanical grinding. Overall, the mechanical grinding technique is the most suitable practice which can serve as the suitable method for repairing the weld defect if the repaired focus area received high impact loads.
\end{abstract}

Index Terms: weld repair, defect, A36 steel, carbon arc gouging, mechanical grinding.

\section{INTRODUCTION}

In fabrication, welding process is one of the important joining processes. It is widely used to join metals using metals or fillers. In order to extend service life of weld joint, inspection and maintenance need to carry out. Defect or damage can occur in the weldment during fabrication or during operation in service. If defects or damages are detected at the weld joint, it is necessary to carry out weld repair to extend the service life of weld joint. Weld repair usually comprises of mechanical removal of weld part and redisposition of the filler wire using the same parameters. Repair the remaining part of the weld will cause the additional thermal cycle, which are responsible for significant microstructural changes and mechanical properties of the material. Carbon steel material is known to be metallurgically 'sensitive' to heat input, Since the weld repair are subjected to additional thermal cycle which could result in degradation of both the HAZ and weld deposit on

Revised Manuscript Received on February 21, 2020.

* Correspondence Author

NurAzida CheLah*, Fabrication \& Joining, University of Kuala Lumpur Malaysia France Institute (UNIKL MFI), Selangor, Malaysia.

Muhamad Hellmy Hussin, Fabrication \& Joining, University of Kuala Lumpur Malaysia France Institute (UNIKL MFI), Selangor, Malaysia.

(C) The Authors. Published by Blue Eyes Intelligence Engineering and Sciences Publication (BEIESP). This is an open access article under the CC BY-NC-ND license (http://creativecommons.org/licenses/by-nc-nd/4.0/) carbon steel

ASTM A36 is a low carbon steel that exhibits good strength coupled with formability. It is easy to machine and fabricate and can be securely welded. ASTM A36 steel is a common structural steel that can be galvanized to provide corrosion resistance. This type of carbon steel is widely used in fabrication today around the world in nearly every industry fabrication such as construction, pipelines, machinery structures and ship building. ASTM A36 steel is easy to weld using any type of welding methods and the welds formed are of excellent quality. There are many types of welding process can use to weld the ASTM A36 such as arc welding, metal inert gas welding (MIG welding) and etc.

Defect can occur in the weldment of carbon steel during fabrication or during operation in service. If the defect is detected at area of the weldment and was acceptable to repair, it becomes necessary to carry out weld repair to extend their service life. Under the rules and guidelines published by classification societies on pipe fabrication and installation, and critical offshore structures, not more than two welding repairs may be carried out in the same area. The rule is imposed perhaps because weld repairs are generally uneconomical and because of a lack of accurate knowledge on the effects of repeated weld repairs on the properties of the weld. However, much will depend on the type of material being welded and the process in use.

The defect may be removed by carbon arc gauging and grinding or machining. Carbon-arc is the most practical that is not recommended. When carbon-arc is used the temperature of the base metal should be at least $100^{\circ} \mathrm{F}\left(40^{\circ} \mathrm{C}\right)$. The method usually comprises of removal of part of the weld and redisposition of the filler wire using the same parameters. Repairing the remaining part of the weld will cause an additional thermal cycle, which is responsible for significant microstructural changes. Carbon arc gauging is more significant in affecting the mechanical properties of the material since the process use high heat input during removal of weld part than use mechanical removal method (grinding or machining). If a weldment fails during inspection because of the defect present on a weldment, the welding inspector will review it in order to determine the extent of damage that may be caused by repairing the weld and whether the weldment can fulfill its function if the defect is allowed to remain in place. If the function of the weldment is affected by the defect, the weldment must be discarded and replaced. In some cases, the defect may not affect the functionality of the weldment, in which case it can be left. These determinations are made on a case-by-case basis. 


\section{Repeated Weld Repair and its Influence on Welded Carbon Steel}

If a part requires rework, a thorough welding procedure should be established to minimize the effect of the repair on the remaining portion of the weld. This procedure must consider the procedure used to create the original weld. It must also consider the following such as the condition of the base metal and weld, type of filler metal to be used in the repair, welding sequence and tooling required for the repair.

The final weld's mechanical properties incomplete consideration of any of these factors may result in further rejection of the weld repair and possible failure of the weld when placed into service.Moreover, repairs are expensive and often detract from the appearance of the final weld. Everything within reason should be done to eliminate defects that require costly repairs. Review every flaw and defect in the weld, regardless of its severity in order to determine its causes. It can be suggested that planning the possible corrective action can be taken in the future to eliminate similar problems.

Therefore, the current paper presents the characteristics of distortion that occurred on repeated weld repair of welded carbon steel.It also includes the microstructures change analysis in each welded zones and its mechanical properties after repeated weld repair has been conducted.

\section{MATERIALS AND METHODS}

\section{A. Material Preparation}

A36 low carbon steel is the material that is being used to carry out the experiment. It has a Poisson's ration of 0.26 and a modulus of shear $75 \mathrm{GPa}$ which is $10,900,000$ psi. With thickness of $10 \mathrm{~mm}$ plates of A36, it has minimum yield strength of 36,000 psi. Ultimate tensile strength ranging from $58,000-80,000$ psi.The composition of A36 is shown in Table 1.

Table 1.Element compositions in wt\% of A36 low carbon steel

\begin{tabular}{|c|l|l|l|l|l|l|}
\hline $\mathbf{C}$ & $\mathbf{S i}$ & $\mathbf{S}$ & $\mathbf{C u}$ & $\mathbf{M n}$ & $\mathbf{P}$ & $\mathbf{F e}$ \\
\hline 0.29 & 0.28 & 0.05 & 0.20 & 1.03 & 0.04 & 98.0 \\
\hline
\end{tabular}

\section{B. Welding Parameters and Visual Inspection}

The joint design use in this experiment is single- $\mathrm{V}$ joint according to the suitable selection depends on the $9 \mathrm{~mm}$ thickness. Groove angle of 60 degrees, root face thickness of $3 \mathrm{~mm}$ and a root opening of $1 \mathrm{~mm}$ gap.

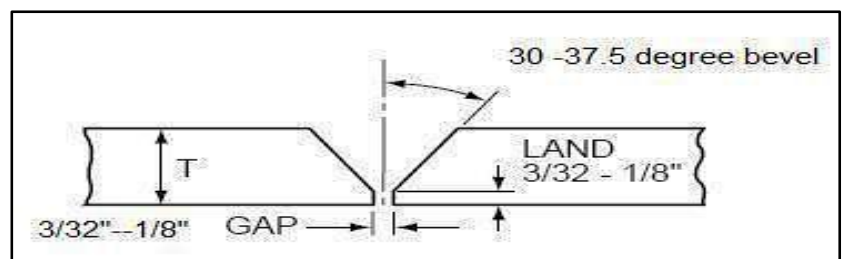

Fig. 1 Side view of single groove butt weld

In this experiment, SMAW process was carried out to join the specimen. SMAW is an early arc welding process ever invented. It is the simplest and most versatile process for welding ferrous and several types of non-ferrous metal. In this work, it requires multi pass Weld joint to fill the joining.

\section{Method of Weldment Removal}

The specimenswere prepared in repeated weld repair work, in order to collect the data that is related to the effect of repeated repairwork. In this project, two type of removal method are used for removal of part of the weld it is carbon arc gauging and grinding method.

Grinding method is one of the mechanical methods for weld part removal. This method is simple but slow compared to carbon arc gauging. This process requires grinding machine to grind the area for removal of weld part. This process should be carefully done to ensure of not removing the adjacent area of weld. Weld defects shall be removed by grinding with carbide burr cutters only. Abrasive-type wheels and stones are not allowed on the interior or the exterior of weld.

Electric arc in air carbon arc gouging is generated between the tip of a carbon electrode and the workpiece. The metal becomes molten and high velocity air jet streams down the electrode to blow it away, thus leaving a clean groove. The process is simple to apply (using the same equipment as SMAW process), has a high metal removal rate, and gouge profile can be closely controlled. Moreover, the DC (electrode positive) is normally preferred for steel and stainless steel. See Table 2 and 3.

\section{Microstructure Analysisand Mechanical Testing}

In this study, macro and microstructure examination was conducted in order to carry out the analysis of microstructure effects after repeated weld repair.

Tensile test was used to determine the strength of the welded material and to predict the force that the material able to withhold under different load of force. Ultimate tensile strength and maximum elongation can be determined. Additionally, bend test is carried out to study the ductility of a material and the bend strength that can be used to determine whether a material will fail under pressure. Another test is hardness test mainly to identify the hardness of the metal at heat-affected zone (HAZ), base metal (BM) and fusion zone (FZ) under microscopic. The test was conducted in order to indicate when the material hardness starts changing from ductile to brittle scenario. Moreover, preparation of the specimens is important to ensure the data given are correct.

\section{RESULTS AND DISCUSSION}

\section{A. Angle of Distortion}

The angle of distortion was measured using 180-degree protector angle and the data was recorded manually. This observation is to determine the change of angle distortion when repeated weld repair were carried out. Fig. 2 shows the angle of distortion increases when the number of repeated weld repair increases. The increasing of angle distortion from show specimen repair using carbon arc gauging is more significant compared to the specimen repair using mechanical grinding. The angle of distortion for the specimen without been repair is $5^{\circ}$. Then, the angle increases for the specimen once repair using carbon arc gauging is $12^{\circ}$ and for the specimen repaired using mechanical grinding is $6^{\circ}$.

Published By: 
The angle of distortion continues to increase, for the two times repair process. It shows that thespecimen that used carbon arc gauging process, the angle of distortion is $14^{\circ}$ increased to $15^{\circ}$ and for specimen repaired using mechanical grinding shows an increment from $8^{\circ}$ to $13^{\circ}$. The change of angle distortion for the specimen repair using mechanical grinding are not much increase for each number of repair process compere to repair process using carbon arc gauging.

Table 2 Shielded metal arc welding parameter

\begin{tabular}{|c|c|c|c|c|c|}
\hline \multicolumn{2}{|c|}{ Shield Metal Arc Welding } \\
\hline Pass/Layers & Travel speed (mm/s) & Current (AMP) & Voltage (V) & Electrode \\
\hline Root pass & 2.92 & $75-80$ & $20-27$ & E6013 & E6013 \\
\hline Second pass & 2.09 & $80-85$ & $20-27$ & 3.2 \\
\hline Third pass & 2.14 & $80-85$ & $20-27$ & E6013 & 3.2 \\
\hline Capping & 2.21 & $85-90$ & $20-27$ & E6013 \\
\hline
\end{tabular}

Table 3 Operating data for air carbon arc gouging

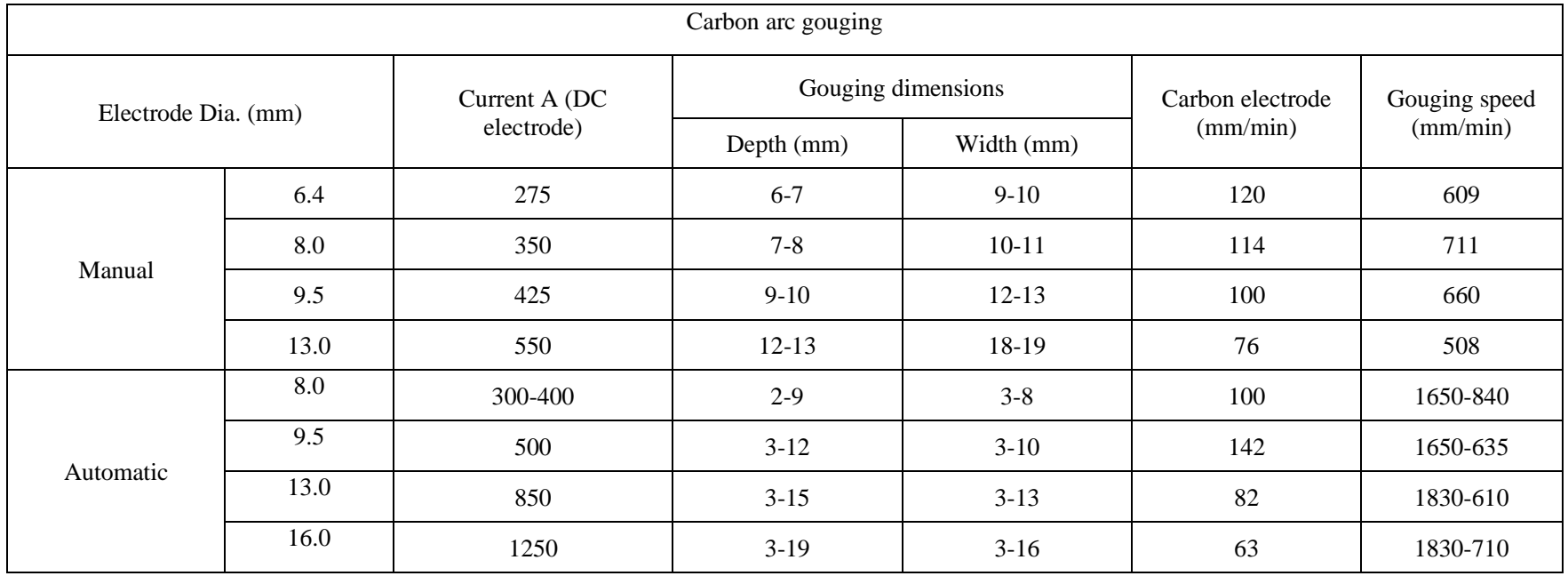

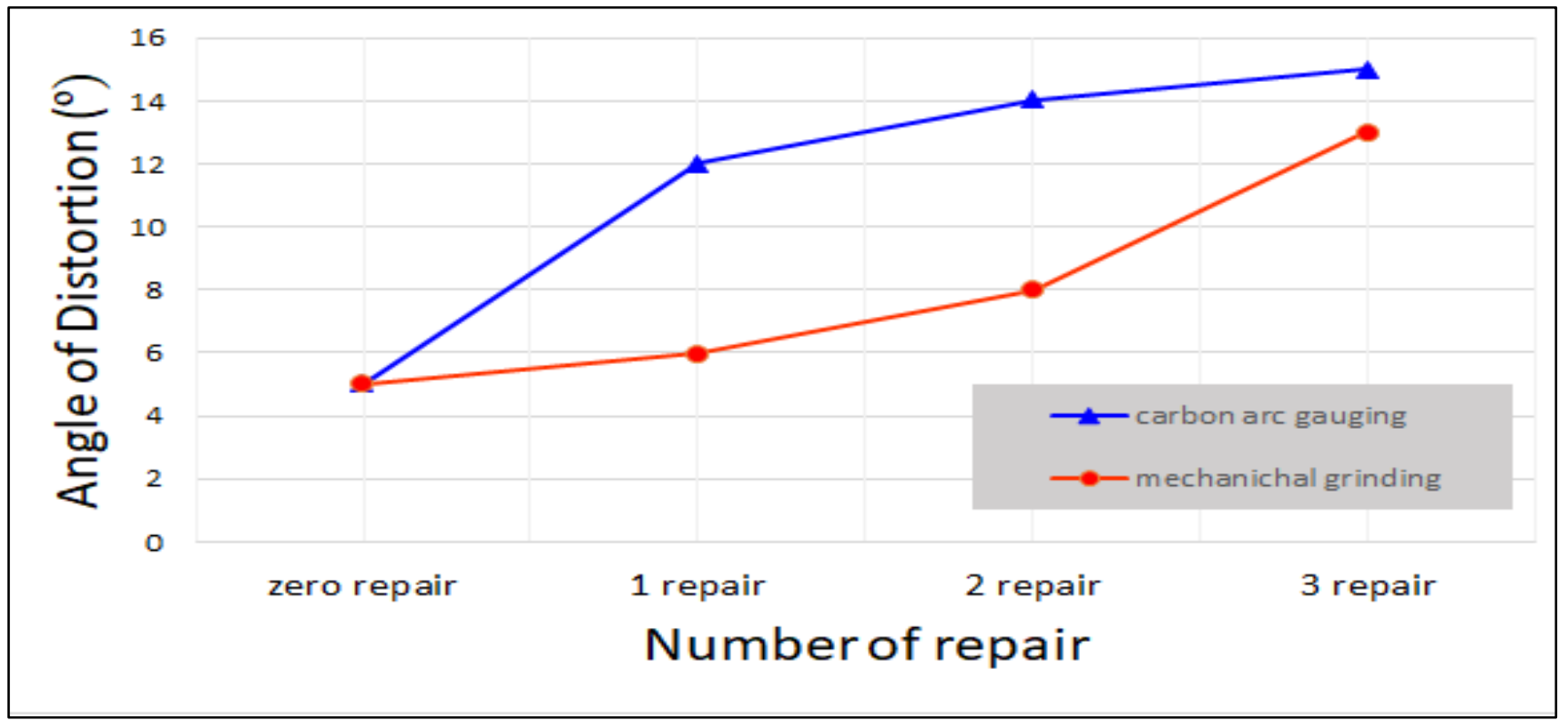

Fig. 2 Angel of distortion for both methods of repair processes.

The change of angle distortion is noticeable for the specimen repaired using carbon arc gauging and it shows that the repair process using carbon arc gauging is more significant for distortion to occur compared to repair using mechanical grinding.This is due to the high heat input involved during repair using carbon arc gauging compared to mechanical grinding. In this case, repeated heat input influenced the increase of angle distortion because in single-V welded joint, the first weld run produces longitudinal and transverse shrinkage and rotation.

Published By: 


\section{Repeated Weld Repair and its Influence on Welded Carbon Steel}

Meanwhile, the second run caused the plates to rotate using the first weld deposit as a fulcrum, and non-uniform contraction will produced angular distortion. Therefore, for the welded joint that involved multi-repair welding process at the same area, must be carefully focused especially in controlling the cooling time in order to reduce the distortion. However, in this case the same cooling time applied but the difference is the heat input of the method use, and the number of sequence the repair involved.It shows an increment of distortion angle for both method.

\section{B. Macro and Microstructure Analysis of Repair and Unrepaired samples}

Macrostructure result provided in Fig. 3, 4 and 5 shows significant difference of observation. It shows that the weld shape was consistent for all samples, and this was to be expected since the joint geometry was machined in the same fashion prior to welding with the same parameters. Weld area size was different between all samples, because the difference of theremoval part method that affect the joint geometry. The weld area size increaseswith the number of repair process. This could affect theweld removal part and also reduction of the weldment. The main difference significantly shows by the size of HAZ and it is indicated that the repair method using carbon arc gauging increased the HAZ size compared with repair method using mechanical grinding in Fig. 3 and 4. The size of HAZ was significant especially for sample using carbon arc gauging compared to mechanical grinding, as shown in Figs. 4 and 5. Moreover, the repair process using carbon arc gauging shows more significant difference especially on the geometry changes because of the arc used during the repair process. This could leads to non-uniform geometry shapecompared to the mechanical grinding's repair process.

The repeated number of repair using carbon arc gauging samples were compared to the repeated number of repair using mechanical grinding samples in order to study the their microstructure changes after repair work using both method.
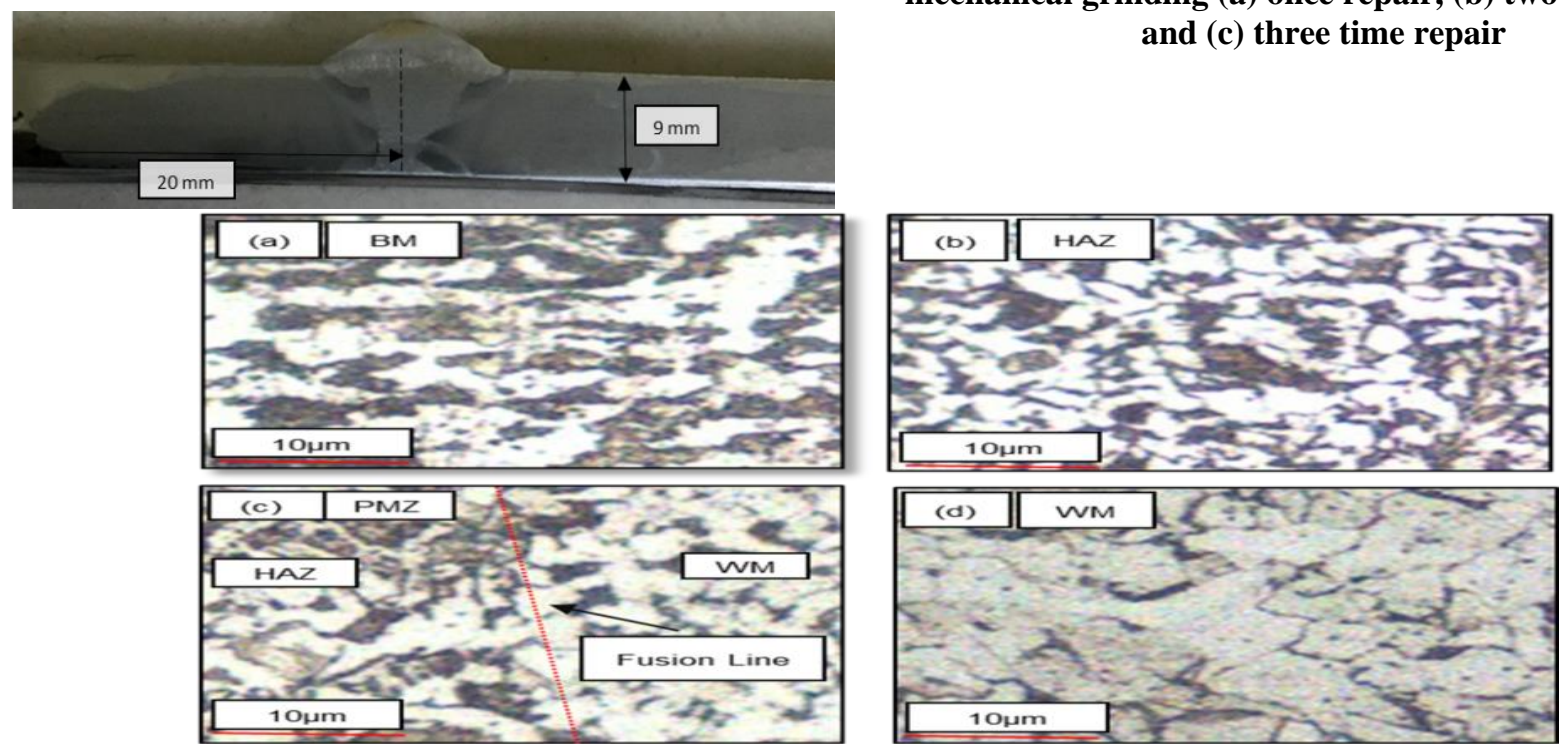

Fig. 6 Microstructure images of welded sample with and without repairing work (a) base metal,(c) heat affected zone,(d)partial melted zone and (e) weld metal
Fig.3 Macro etch cross-section of samples welded without repair work
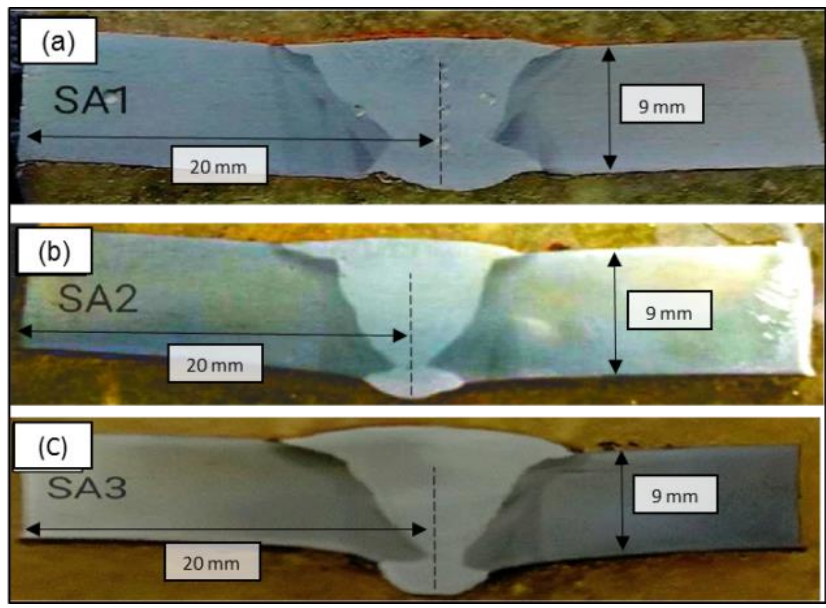

Fig.4 Macro etch cross-section of samples repair using carbon arc gauging (a) once repair, (b) two times repair, and (c) three time repair
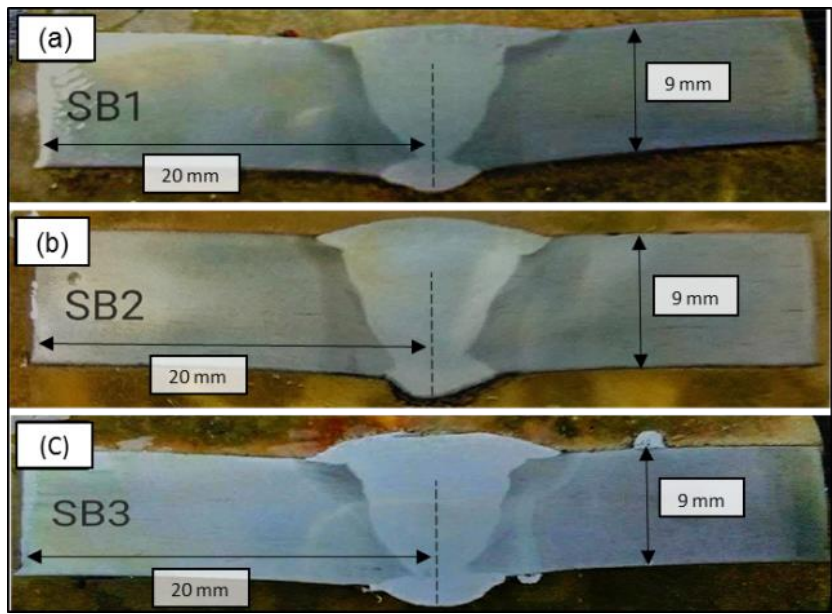

Fig.5 Macro etch cross-section of samples repair using mechanical grinding (a) once repair, (b) two time repair, and (c) three time repair
Published By:

717 Blue Eyes Intelligence Engineering \& Sciences Publication 


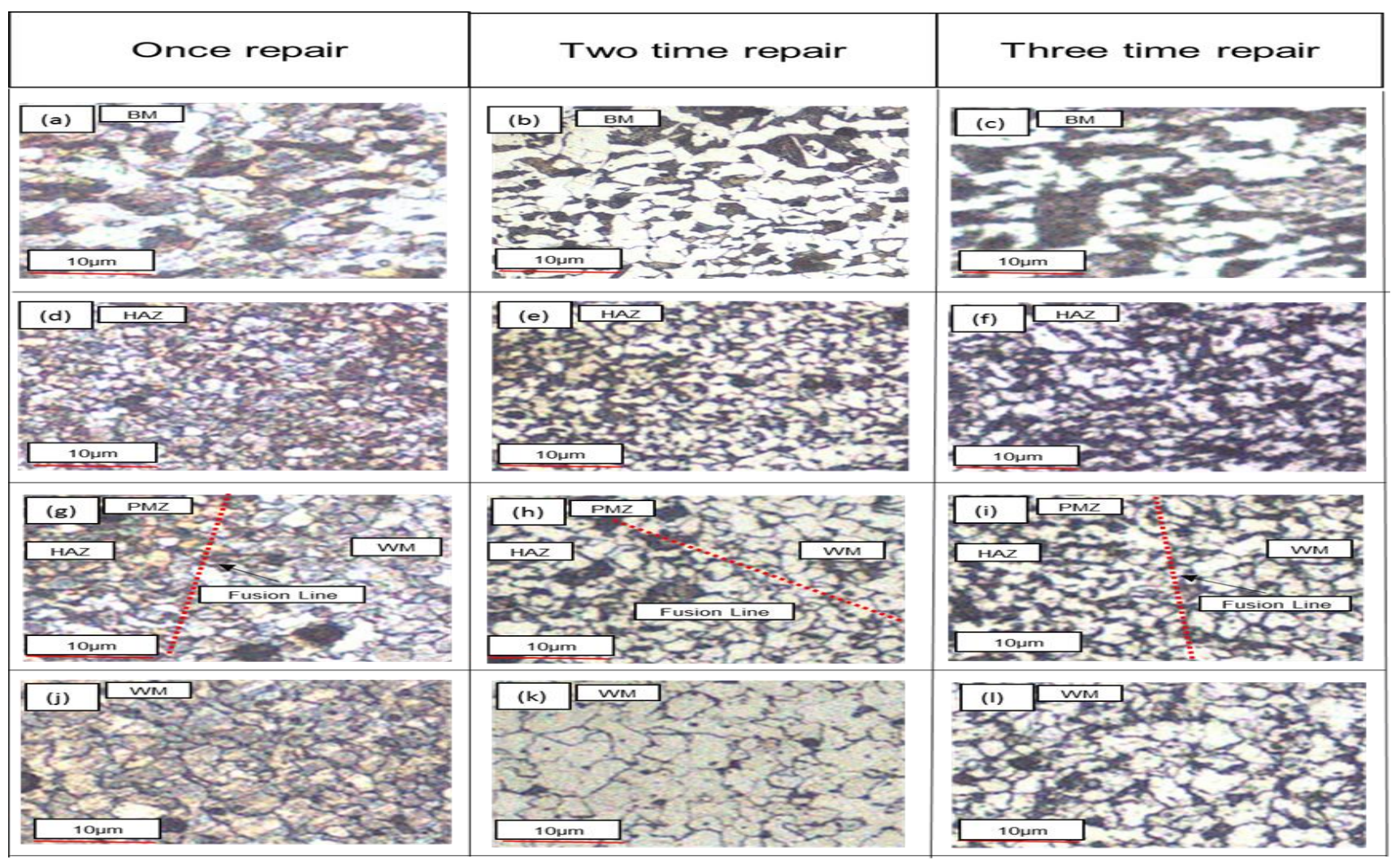

Fig. 7 Microstructure images of welding repair sequence using carbon arc gauging in (a) base metal, (d) HAZ, (g) PMZ (j) weld metal.

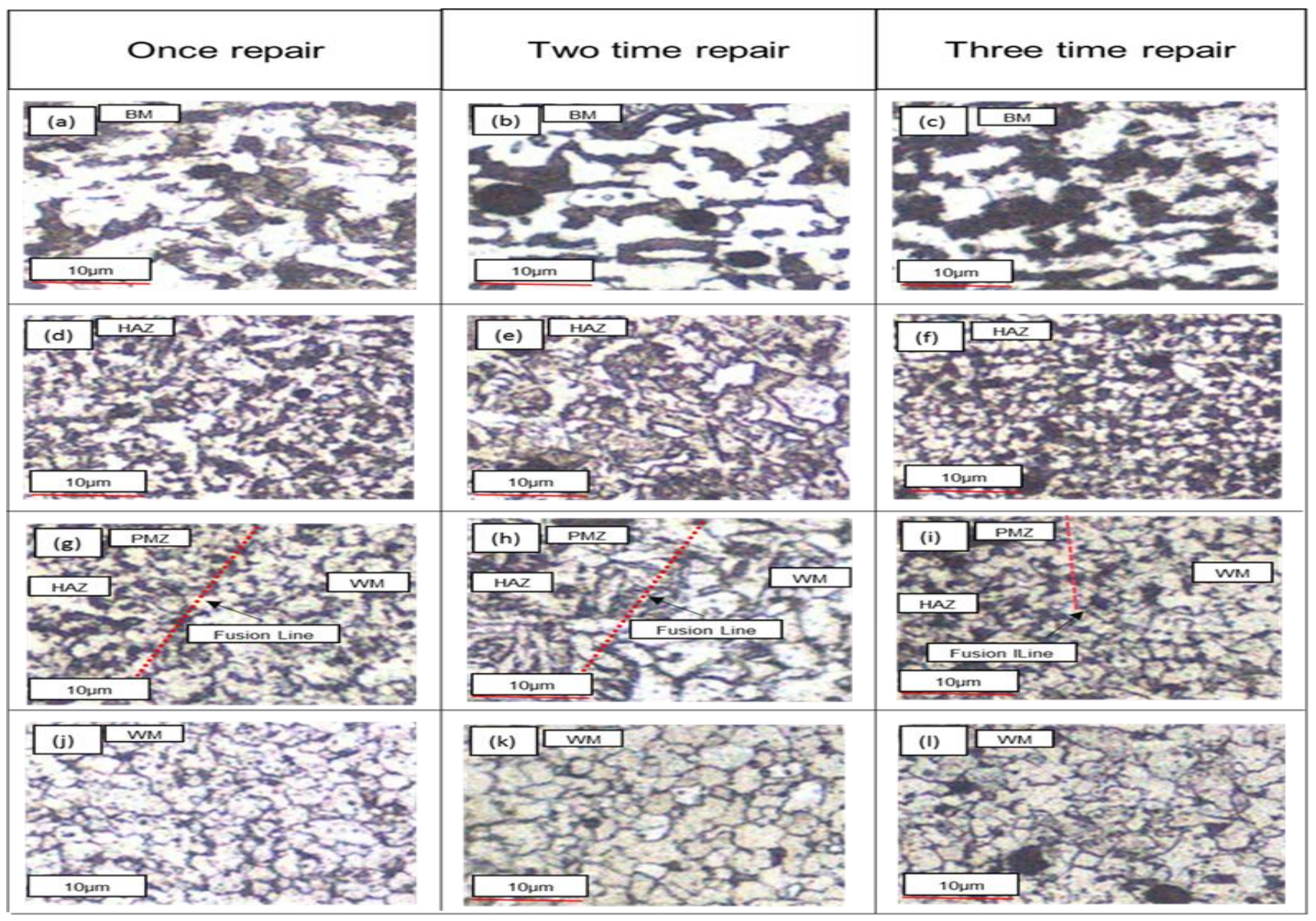

Fig. 8 Microstructure images of welding repair sequence using mechanical grinding in (a) base metal, (d) HAZ, (g) PMZ (j) weld metal.

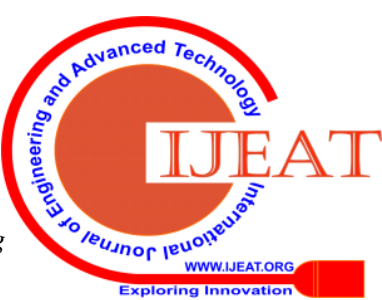


As shown in Figs. 4 to 8, it shows there are no significant changes at BM region because this region was not affectedby the heat generated during welding process. This is suggested to be the reason why the BM shows similar observation of its similar microstructure.

As shown in Figs. 7 and 8, it is indicated a similar pattern of fusion boundary and no significant microstructural changes was observed for all specimens even the number of repeated repair increases. It is observed that the larger grain size was observed in BM region compared to HAZ region for all specimensfor both mechanical grinding and carbon arc gauging welded joint. It can be suggested that this could be the reason of repeated weld sequence applied for all specimens.
As expected, the HAZ region was affected by the repeated heat during welding and repair process. From microstructure result at HAZ region, the grain size of HAZ on repaired specimen using carbon arc gauging shows coarsergrain size comparedto thespecimen using mechanical grinding. This could be attributed by the heat generated during repair using carbon arc gauging compared to the method using mechanical grinding. Since the carbon arc gauging is a method that used an arc for weld removal part, it can be said that this could leads tothe microstructural difference in HAZ compared to the repair method using mechanical grinding. The microstructure of HAZ region shows significant changes when the number of repeated repair increases, and this could be the attributed by the heat applied especially at the same area.
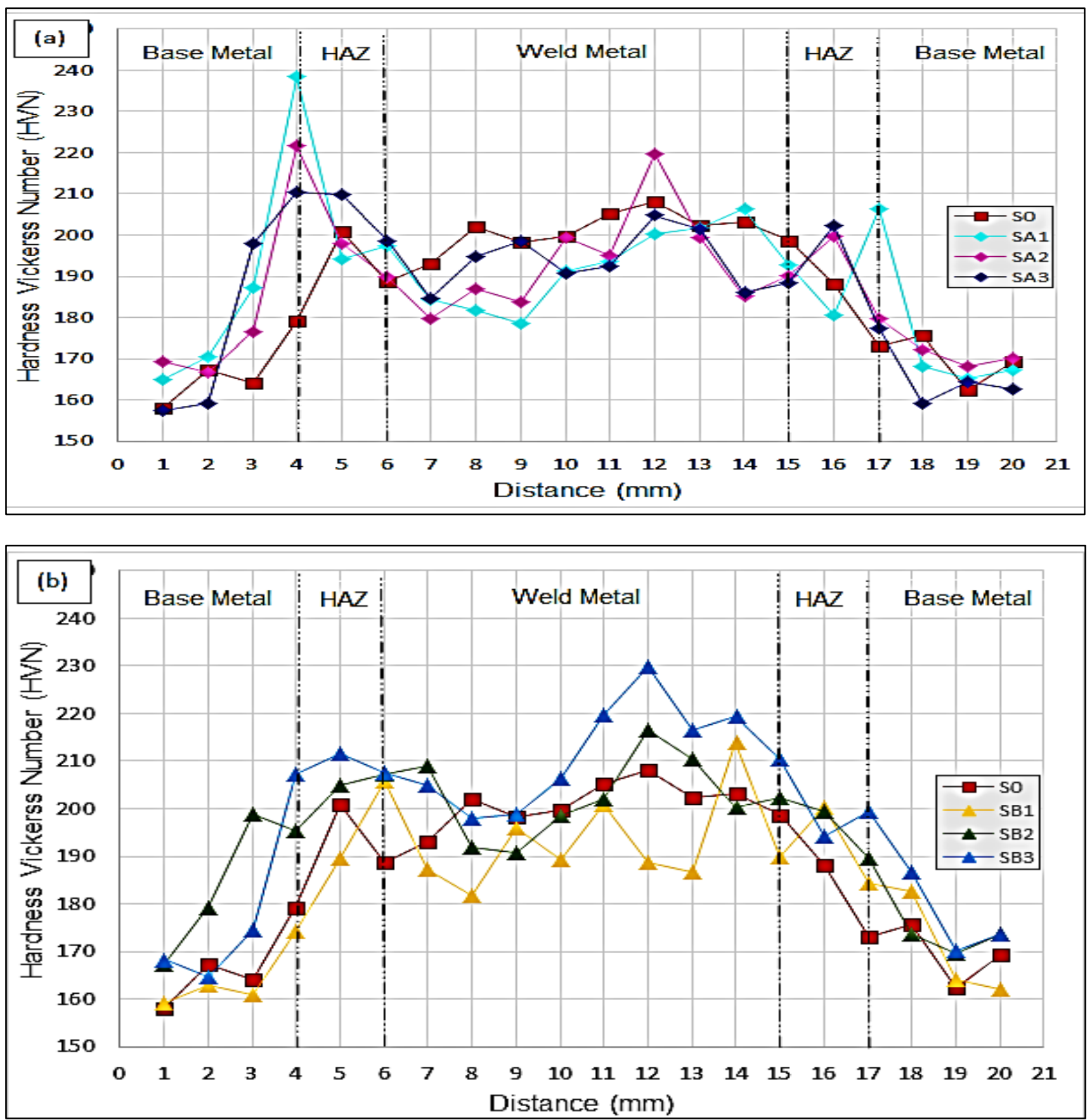

Fig. 9 Hardness profile of repeated weld repair using (a) carbon arc gauging and (b) mechanical grinding. 


\section{Hardness of Repair and Unrepaired samples}

Hardness profile of the welds was illustrated in Fig. 9. The average hardness results of three regions which comprises of $\mathrm{BM}, \mathrm{HAZ}$ and $\mathrm{WM}$ of all samples indicate that the hardness were relatively high at the HAZ for all sample. From the hardness profile result that shown in figure, the value of hardness at the area of HAZ will increase when the number of repeated repair using both methods of repair increased. This is suggested because of the area of HAZ that was affected by the heat during welding and repair processes. Hardness value was low at BM region show compared to HAZ and WM region for all specimens and this because the area was not affected by the heat during repair and welding processes.

It shows that the hardness profile for repairedsample using carbon arc gauging show an increase in the hardness value at the area of HAZ when the number of repeated weld repair increased as shown in Fig. 9. For the weldment area the hardness value number decreases as the number of repeated weld repair increases and this is suggested due to the repeated weld sequence applied and replaced with the new weldment during the repair process.

For sample repair using mechanical grinding the change or the increasing of the hardness value at BM, HAZ and WM region are not significant compared to the repair using carbon arc gauging. The hardness value at HAZ region for sample repair using mechanical grinding shows an increase at sample once and two time repair only and decrease at three times repair sample. For the hardness value at WMregion it shows that no significant difference was found for repairedsample using mechanical grinding compared to the repairedsample using carbon arc gauging that show the decrease on the weldment area.

\section{Bend Test of Repaired and Unrepaired samples}

Bend test has been conducted as a method for measuring stiffness and yield properties of materials A36 after the material was repaired using carbon arc gauging and mechanical grinding. Bend test for ductility provide a simple way to evaluate the quality of materials by their ability to resist cracking or other surface irregularities during one continuous bend. In certain cases the bend test can determine its tensile strength. Having two method of repair welding has led to a finding that in terms of ultimate maximum stress as it confirmed by bend test. From the findings, the value of maximum stress before the fracture occurred for both methods of repair was decrease when the number of repair increases. As shown in Fig. 10, it is indicated that all the sample that involved with repair work was fracturedthat is occurred at weldment boundaries area which is HAZ. According to the ASME IX standard for the bend test requirement, it is stated that if the sample indicate fracture zone at any area of weldment, thus the sample would be rejected.

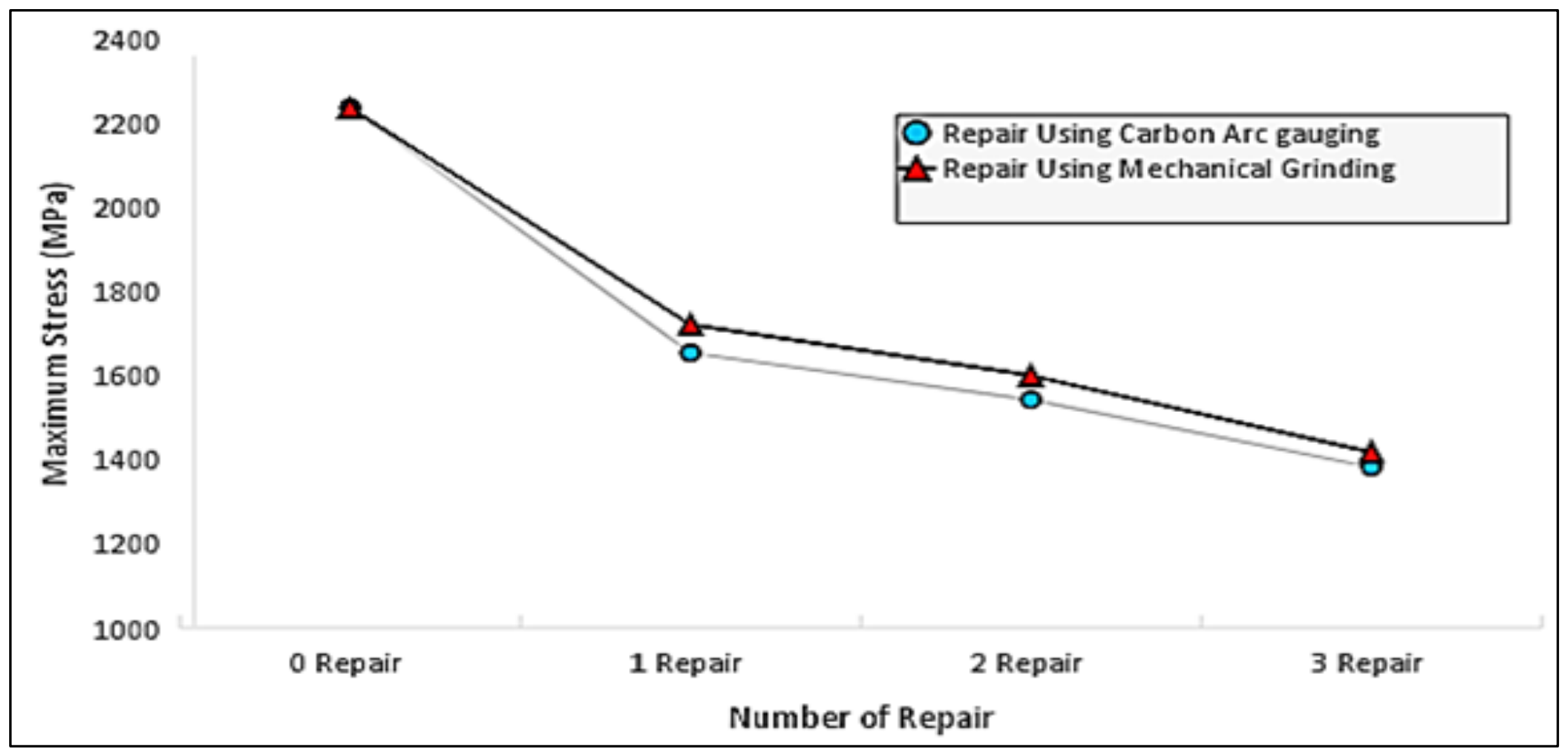

Fig. 10 Maximum stress before fracture of the repeated weld repair

\section{E. Tensile Test}

Tensile testproved useful in further understanding the effects of repeated welding operations on the mechanical properties of ASTM A36. From the stress-strain curve, as shown in Fig. 11,the sample without repaired (S0) shows an ultimate tensile stress of $613 \mathrm{MPa}$ and the total strain is $16 \%$. It also indicates that the sample has low ultimate tensile strength but high strain (ductility). Moreover, the ultimate tensile strength was found increases as the value of the yield strength increases. In this case, the sample that involved with

repair work shows to have high ultimate tensile strength compared to the unrepaired sample but the ductility of the sample was decrease.

For the repaired sample using carbon arc gauging, it was observed that the sample fractured at the HAZand for the repairedsample using mechanical grinding, only two samplesfractured at the HAZ and other one break at BM. 


\section{Repeated Weld Repair and its Influence on Welded Carbon Steel}

For sample repaired using mechanical grinding that involved with one time repair, the sample was found fractured at BM.Ductility of the sample was found decreasesas the number of repeated of weld increases. It was proved by the decreasing of the elongation of the sample before fracture. It is also in agreement with the high hardness value at the area of HAZ. It is also indicated that the sample that involved with repair work for both methods shows to have high ultimate tensile strength with low ductility compared to the unrepaired sample that has low ultimate tensile strength but high ductility.
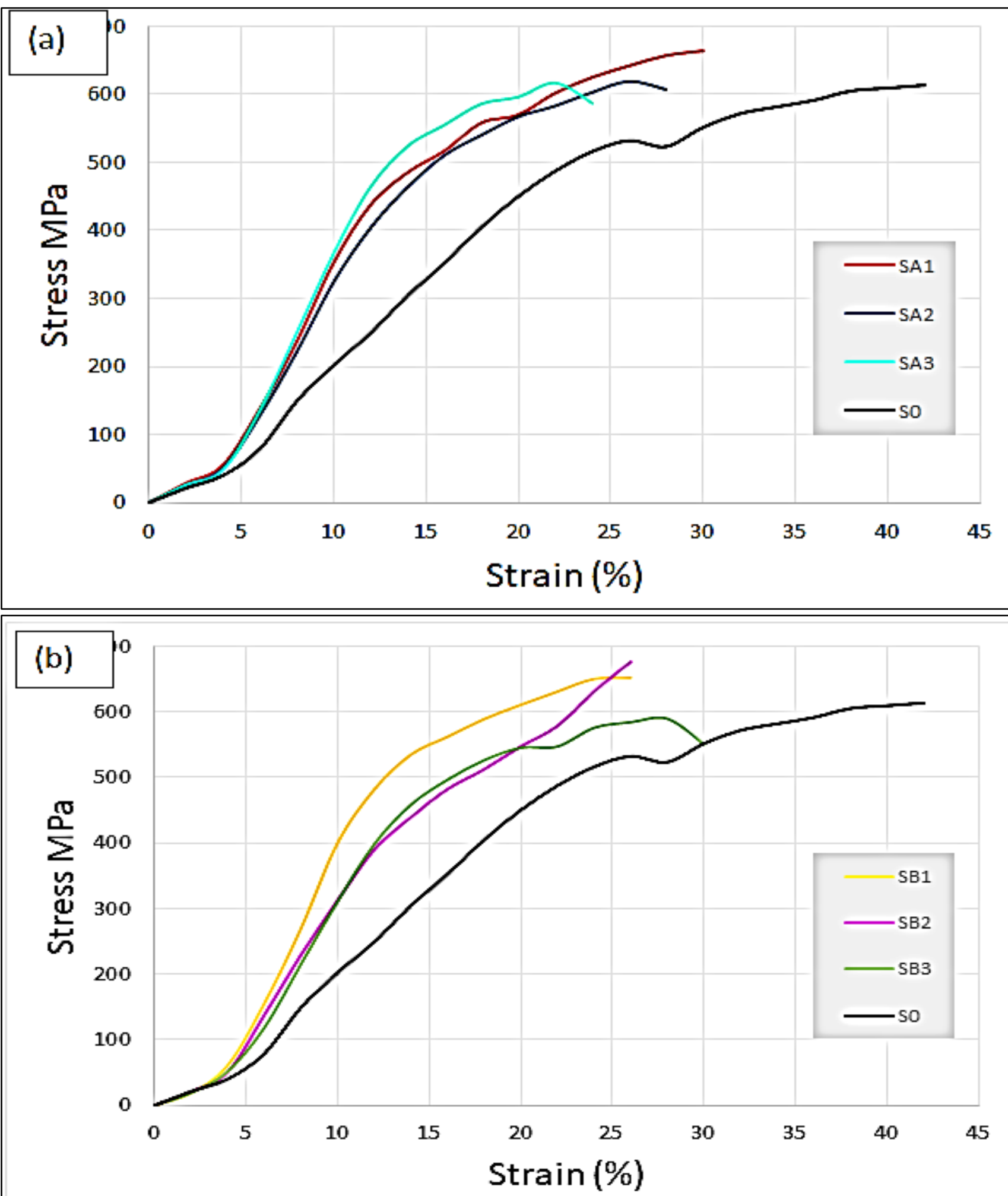

Fig.11 Stress-strain curves representing tensile behavior for the repeated weld repair using (a) carbon arc gauging and (b) mechanical grinding 


\section{CONCLUSION}

Repairs are expensive and often detract from the appearance of the final weld. Weld repair also affect the properties of the material and the weld joint itself caused the change of mechanical properties and the microstructure of the material. ASTM A36 is not suitable to apply the repairing process more than one time repair. The repair process using carbon arc gauging is more significant in changing the properties of the material since the process involved high current and heat during removal part of the weld compared to the repair process using mechanical grinding. Moreover, HAZ is the most significant region affectedby the repairing process because this area are not melted but was been heated during repairing process compared to BM and WM. The ductility of the ASTM A36 having reduction due to the increase of number of repair process. The angle of distortion increases when the number of repair process at the same area increased. Based on the study, it can be suggested that no indication of quality enhancement if the weld undergo more than one time repairing work.

\section{REFERENCES}

1. American Welding Society Committee on Structural Welding. (2015). Structural Welding Code- Structural. In A. A. Standard, AWS D1.1, 23rd Edition. American National Standards Institute.

2. Annette O'Brien. (2004). Arc Welding Power sources. In W. h. committee, Welding hand book, 9th edition, voulume 2 (p. 10). Miami : American Welding Society.

3. Asibeluo, I., \&Emifoniye , E. (2015). Effect of Arc Welding Current on the Mechanical Properties of A36 Carbon Steel Weld Joints. SSRG International Journal of Mechanical Engineering (SSRG-IJME).

4. Bruce R. Somers. (1993). Introduction to the Selection of Carbon and Low-Alloy Steels. In A. International, ASM Handbook, Volume 6: Welding, Brazing, and Soldering (p. 405). Lehigh University: ASM International.

5. C.-M. Lin et al. (2012). Effect of repeated weld-repairs on microstructure, texture, impact. Engineering Failure Analysis.

6. Chotěborský, R., Hrabě, P., \&Kabutey, A. (2011). Change of mechanical properties in substrate during rewelding deposit. Faculty of Engineering, Czech University of Life Sciences Prague, 105-109.

7. GUPTE, S. V. (2004, July). Inspection and Welding Repairs of Pressure Vessels. Retrieved from NDT NET : http://www.ndt.net/article/v09n07/rajesh/rajesh.htm

8. Katsas, S., Nikolaou, J., \&Papadimitriou , G. (2006). Microstructural changes accompanying repair welding in 5xxx aluminium alloys and their effect on the mechanical properties. Materials and Design 27, 968-975.

9. M. Siva Prasad. (2015). The Effect of Repeated Repair Welding on the Corrosion Behaviour of Austenitic Stainless Steel and Mild Steel Dissimilar Weldment. International Conference on Advances in Materials, Manufacturing and Applications.

10. Munro Cameron. (2013). The Effects of Repeated Weld Repairs on the Mechanical Properties of Copper-Nickel Pipe Joints. Defence R\&D Canada - Atlantic.

11. O'Brien, A. (2004). Arc cutting and Gauging. In T. W. Committee, AWS Welding handbook, 9th edition, volume 2 (p. 654). Miami: American Welding Society.

12. P. Dong and J. Zhang. (2002). Effects of Repair Weld Length on Residual Stress Distribution.

13. TWI Global. (2017). Retrieved from Job knowledge: http://www.twi-global.com

14. Vegaa, O., Hallena, J., Villagomezb, A., \&Contr, A. (2008). Effect of multiple repairs in girth welds of pipelines on the mechanical properties. MATERIALS CHARACTERIZATION 59, 1498 - 150 7.

15. Zamanhuri, P. Z., Khalid, N., \&Daud, A. A. (2017). EFFECTS OF POST WELD HEAT TREATMENT ON HARDNESS VALUE OF A36 CARBON STEEL WELDED JOINTS BY SHIELDED METAL ARC WELDING. ARPN Journal of Engineering and Applied Sciences.

\section{AUTHORS PROFILE}

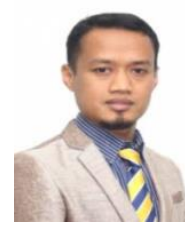

Muhamad Hellmy Hussin, is a lecturer in University of Kuala Lumpur Malaysia France Institute (UNIKL MFI) located at Bandar BaruBangi, Selangor for fourteen years. His expertise is in Innovation and Engineering Design, and also in Corrosion and Failure Analysis. He did his Bac. (Hons.) in Industrial Production Management at the University Nice Sophie Antipolis (UNSA), France, and then pursued his Master Degree in Innovation and Engineering Design at University of Putra Malaysia (UPM) Serdang, Selangor.Over the last eight years he becomes involved in welding and joining research works. And since then he has continued his research and involved in Corrosion and Failure Analysis research areas, Corrosion and failure analysis works. Now, he pursue his PhD in (Mechanical), focusing on High Temperature Corrosion in Hot Gases Environment. He has published articles and journals mainly in Welding and Joining, Corrosion degradation and Failure Analysis research works.

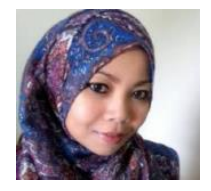

Dr. NurAzida CheLah, is a senior lecturer on Corrosion degradation and Failure Analysis studies at the University of Kuala Lumpur Malaysia France Institute (UNIKL MFI), Bandar BaruBangi, Selangor. She did her Bac (Hons) in Materials Science and then pursued her Master degree in Mechanical Engineering majoring in Fatigue failure Assessment on welded joint at University of Putra Malaysia (UPM) Serdang, Selangor. Her PhD focusing on High Temperature Corrosion Study on Aluminium Welded Joint at The National University of Malaysia (UKM), Bangi, Selangor. And since 2007 she started writing an articles and journals mostly on Fatigue Assessment Analysis, Welding and Joining, Corrosion degradation and Failure Analysis Studies. 